\title{
Openness, resource sharing and digitalization - an examination of the current trends in Finland
}

\author{
Farmo Saarti \\ Library Department, University of Eastern Finland, Joensuu, Finland, and \\ Kimmo Tuominen \\ University of Helsinki, Helsinki, Finland
}

\begin{abstract}
Purpose - Although resource sharing between scholars is evolving rapidly, This paper uses paper-based interlibrary lending (ILL) procedures in the service repertoire of academic libraries. However, the current business model of acquiring toll-access journals and e-books does not seem to fit very well with traditional ILL practices. In addition, the new models of peer-to-peer resource sharing between academics seem to be much more effective than ILL. Scholars arrange access to the needed publications by using legal (buying, exchanging) and illegal means (Sci-Hub, etc.). Furthermore, the demands for open access have increased, voiced not only by librarians and science funders but also by politicians. This development might change the scholarly publication ecosystem, even though older publications are still likely to remain closed.

Design/methodology/approach - This paper contrasts the ILL and usage statistics of Finnish university libraries with the use of ResearchGate, a popular academic social network, which we treat as an example of a peer-to-peer sharing service.

Findings - Based on the data, there seems to be a change of paradigm in the resource sharing: the traditional ILL seems to be decreasing and becoming more like a niche service and the digital use and use of social media peer-to-peer resource sharing applications seem to increase rapidly.

Originality/value - The paper examines current resource sharing trends. The analysis is based on the data of Finnish resource sharing, interlibrary lending and ResearchGate usage.
\end{abstract}

Keywords Finland, Resource sharing, Interlibrary lending, University libraries, Digitalization

Paper type Research paper

\section{Introduction}

The operational environment of traditional interlibrary lending (ILL) activities began to evolve rapidly during the 1990's. Owing to the spreading of internet technologies and network-based services, scholarly communication tools changed, and there has been a move from print journals to e-journals. From the beginning of this millennium, we have witnessed the transformation of monographs from physical documents to e-books. Recently, there has been a rise of different types of digital services for academic communities for sharing ideas and published results (Muhonen and Saarti, 2016), as well as an emergence of MOOCs and other kinds of digital learning environments.

Advancements in technologies and social practices have led to a paradigm change in scholarly publishing and knowledge dissemination. The printed era provided a quite closed environment where library premises and different types of collections of physical entities were of utmost importance in enabling research activities. Digital technologies revolutionized these paper-based processes. In principle, it is nowadays possible to publish, disseminate and discuss research results in real time and without gatekeepers.

The current issue and full text archive of this journal is available on Emerald Insight at: https://www.emerald.com/insight/2398-6247.htm

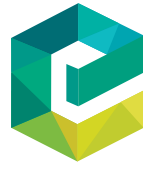

Information Discovery and Delivery

49/2 (2021) 97-104

Emerald Publishing Limited [ISSN 2398-6247]

[DOI 10.1108/IDD-01-2020-0006]
Saarti and Tuominen (2017) depict the ongoing change as a move from the printed world via digital to the post-digital operating environment of science. The recent policy discussion and policy initiatives around open science have speeded up this process. Policymakers and research funders have started to emphasize the need for opening the whole research process and making the publicly funded results of the academic work openly available (European Commission, 2012). The goal of these pursuits is to increase the societal and scientific impact of the scholarly activities.

In the present paper, emphasis is on analysing the changes that have taken place in Finland because we know the Finnish

(C) Jarmo Saarti and Kimmo Tuominen. Published by Emerald Publishing Limited. This article is published under the Creative Commons Attribution (CC BY 4.0) licence. Anyone may reproduce, distribute, translate and create derivative works of this article (for both commercial \& non-commercial purposes), subject to full attribution to the original publication and authors. The full terms of this licence may be seen at: http://creativecommons.org/licences/by/4.0/legalcode

The authors would like to thank Mr Georg Strien from the Federation of Finnish Learned Societies for providing the statistical data of the trends in the institutional exchange of scientific publications in Finland.

This is an edited and more comprehensive version of our presentation and paper at the 2019 IFLA ILDS Conference "Beyond the Paywall: Resource Sharing in a Disruptive Ecosystem."

Received 10 January 2020

Revised 13 February 2020

28 May 2020

8 June 2020

Accepted 11 June 2020 
library system and the infrastructural and political context of academic work and library activities in our native country (Tuominen and Saarti, 2012). However, our remarks are not specific to the Finnish situation but reflect the general changes of scholarly practices and research environments. The study probes how the Finnish resource sharing landscape and ILL practices have changed in the past few decades. The researchers used the Finnish Research library statistics database and analyse ResearchGate (www.researchgate.net/) as an example of the kinds of resource sharing tools that Finnish researchers and academic libraries use in disseminating research information and for generating more visibility to it. To complement our views, the researchers use the statistics generated by the Finnish National Exchange Centre of Scientific Literature.

\section{Digitalization of the interlibrary lending - literature review}

The changes in the operating environment of scholars have affected our conceptions of ILL practices. Resource sharing means much more than lending and sending paper copies, faxes or e-mails between libraries. Resource sharing includes all the types of activities that try to ensure, within the academic and academic library community, the access to all the information resources needed in scholarly work.

There still was a clear trend of increasing printed ILL during the 1990's when especially consortium building lead to a more open use of library collections (Beaubien et al., 2006, pp. 75-76). Digitalization started to increase at the beginning of this millennium, and it affected ILL practices. Jackson (2004, p. 92) defined the rising trends as follows:

- The use of blend of mediated and user-initiated services.

- The percentage of returnables will increase as electronic journals expand in number and print versions are terminated.

- A mixed copyright and license environment will prevail.

- Global interlending and document delivery will increase.

- Turnaround time will be faster, but user expectations will also increase, so that for many requests, turnaround time will still not be fast enough.

- Bibliographic items will be easier to identify.

- New tools will emerge.

A more recent analysis by Posner (2014) stresses the quickly evolving, disruptive information technologies that are changing how the users get access to documents they need. Posner also raises the question of ethical grounds for ILL, i.e. the idea of recycling and the need for global information equity for all.

Digitalization has also transformed the role of academic libraries. Currently there is no monopoly for providing access to digital materials. The digitalization of scholarly publications means, among other things, outsourcing some of the traditional library functions and collections to commercial actors. Furthermore, the rise of social media makes it easier for researchers to distribute and share publications and other documents. It is now wonder why the question of who oversees providing information resources for the academia pops up every now and then. There seems to be a need for reframing the collection policies in the academic library community and, especially, to reflect upon how to make these policies more effective, coherent, and up to date (Baraggioli, 2018; Bjørnshauge, 1999; Vattulainen, 2018).
Another thread of the conversation is the role of the research libraries in ILL or in resource sharing activities more generally. At the turn of the millennium, the consensus seemed to be that libraries are and will be the primary actors in ILL. Some library professionals even predicted that the amount of ILL would be growing in the future. Generally, our expectations have been premised on the notion that new digital services would help to manage the ILL processes (Connolly, 1999). It seems that the turn to digital, paywalled journals decreases the need for ILL, but there have also been notions of fluctuation in the ILL trends of digital journals or even some increase (Yue and Syring, 2004; Williams and Woolwine, 2011).

The variation of ILL trends seems to be based on the culture of different nations, the collections policies of libraries and educational policies of their host institutions, as well as disciplinary differences. For example, the long-time trend analysis of French University libraries from 1975 to 2000 revealed that the growth of hybrid collection, especially the increase in the e-resources, started to decrease the total amount of ILL transactions from the year 1994 (Boukacem, 2003).

At the same time, some authors saw that the digital operating environment is not without pitfalls. The use of digital tools might lead to new kind of problems or obstacles, for example, within the realm of copyright law, and that is why libraries should perhaps specialize only in the so-called hard-core ILL, i.e. in the distribution of the printed, less-used materials among institutions (Prowse, 2000). The discussion on the role of academic libraries as nodes in the evolving post-digital resource sharing environment and the role of the so-called end users continues (Saarti, 2018).

Maybe the major possible game changer in the future will be the rapid growth in the open access (OA) publishing that enabled the direct use of the resources without any paywalls. Piwowar et al. (2018) estimated that " $27.9 \%$ (95\% CI [27.6-28.2]) of all DOI-assigned journal articles are OA, using the Crossref-DOI sample." That amounts to about 18.6 million OA articles. The recent policy statements to the rapid immediate OA may soon accelerate this trend, e.g. the so-called Plan S requires OA from the year 2021 onwards (European Science Foundation, 2020).

\section{Statistical trend analysis as a methodological choice}

Parnell and Bresnick (2013, p. 2) state that, academic libraries and other actors need to decide on allocating resources in the best possible manner. This is especially important in the present world where user needs and diversity of resources and services grow at the same time as the libraries must live with shrinking budgets (Muhonen et al., 2011). The decisionmaking process is always a complex one and requires both hard and soft data.

Scenario analysis tries to help an organization in its strategic work, especially in understanding and reorganizing services. It focusses mainly on four areas (Zanoni, 2011, p. 68):

1 What is the current "embryonic" vision of the organization?

2 What is the current competitive structure?

3 What is the general scenario?

4 What is the industry scenario? 
The idea is to understand where the organization is at the present and to analyse the operational environment to find out to what direction the organization should move.

The traditional statistical methods need a long run data to see what has been happening and what might be the future. Owing to the rapid change in the operational environment of academic actors, the use of statistics to predict the future is not without risks. For the practical management and development of academic library services, long-run data is usually not possible. It is clearly discernible that disruptive technologies may change the rules of the game and in a quite short time. A good example is the revolution caused by the digital dissemination of academic journals that started in the nineteen nineties and changed the ways articles are accessed and used (Solomon, 2012).

However, a sound trend analysis based on statistical facts is one of the tools for gathering reliable data for the purposes of scenario analysis. In Finland, the centralized collection of national academic library statistics has been based on the ISO 2789 standard from the year 2002 .

The Finnish Research library statistics database (https:// yhteistilasto.lib.helsinki.fi/?lang=en) gives a comprehensive picture of the Finnish academic libraries. The libraries collect the data annually according to the international library statistics standards and the online version of the database offers statistics from the year 2002. The researchers uploaded the data directly from the database and made the graphics with Excel. In addition, the authors asked and received statistics concerning the trends in the development of Finnish scientific literature exchange.

The researchers have collected the data for ResearchGate usage from the institutional statistics pages of the Finnish universities at ResearchGate. People might express their institutional affiliations in many ways. However, we do not take account of these potential variations in the present paper, i.e. we use only data based on the official name of each university and on how the ResearchGate users describe themselves. Thus, the data might be somewhat unreliable (although ResearchGate checks the authenticity of institutional e-mail addresses).

In the following, the researchers will be analysing the trends in the Finnish academic resource sharing environment and we will also be discussing the possible scenarios for the academic libraries in the future. The study aims to the following research questions:

RQ1. What major trends there have been in the ILL and library resource use in Finland from the year 2002 to 2018 ?

RQ2. How the Finnish academics are using new types of peerto-peer Web-services, especially the ResearchGate?

Based on the afore-mentioned questions, the researchers attempt to speculate the trends of the Finnish resource use and sharing landscape and what it means for the academic libraries and their service provision.

\section{Changes in interlibrary lending and document exchange activities in Finland}

Figure 1 shows the development of ILL in all Finnish universities. A rapid decrease is evident both in national and international ILL. The biggest change has happened in national ILL activities. It seems that the amount of traditional ILL is diminishing although ILL seems still to be important for some research purposes.

Figure 1 ILL trends in Finland 2002-2018

\section{ILL trends in Finland}

\section{0,000}

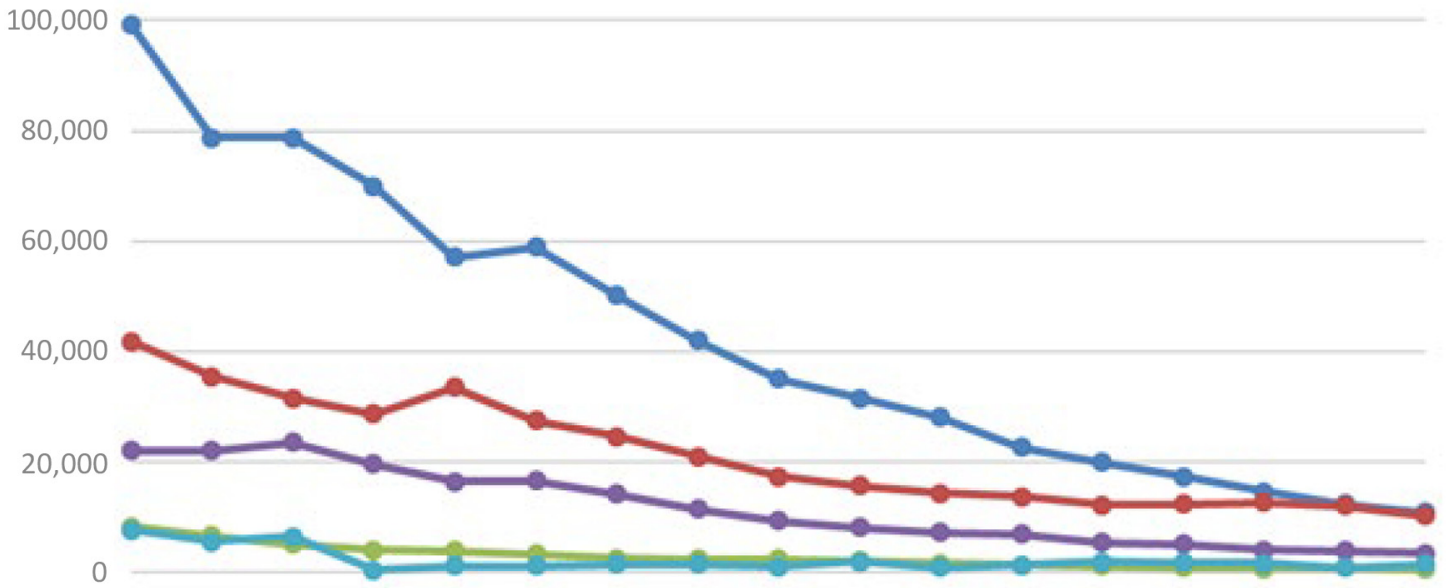

20022003200420052006200720082009201020112012201320142015201620172018

- National ILL, outloans $\quad-$ National ILL, inloans $\quad$-International ILL, outloans
- International ILL, inloans $=$ E-document delivery


It is evident that the E-document delivery has not become a major service between the libraries. Also, the Finnish collections seem not to be interesting for the international ILL market. The language barriers might be the major explanation here.

Figure 2 shows the most probable reason for the decreasing of ILL in Finland. The use of digital resources has been growing dramatically during the last two decades. Especially, e-book revolution seems to have taken place in the Finnish universities. The current trend is that researchers and students seem to use more e-books than e-journals.

When comparing the usage of e-books with the traditional printed book loans, one should note, however, that renewals are not included in the numbers of traditional loans. In addition, the usage numbers of digital materials do not consider how many times the same person has downloaded the same e-book, for example, there is no distinction between the first use and the re-use in the download numbers of digital materials. Another unfortunate fact is that there is no national statistics of e-book usage before 2009. However, the number of the first loans in printed collections has fallen at the same time as the usage of e-books has increased.

One reason for the extensive use of digital resources in Finnish libraries is the FinELib (the Finnish Electronic Library) consortium, which has been so far able to help Finnish universities in making the big deals and acquiring toll-access journals. Larger universities, of course, buy many e-resources outside the consortia, too. University libraries have made e-books and e-journals more familiar to users through different kinds of digital services, marketing efforts and information literacy education. Most of the users nowadays prefer digital media, even though there might still be some academics who love the exquisite scent of dusty papers.

\section{Role of the national Exchange Centre of Scientific Literature in resource sharing}

Finland has a national Exchange Centre of Scientific Literature (ECSL, www.tsv.fi/en/services/exchange-centre-scientific-literature), which belongs to the Federation of Finnish Learned
Societies. The Centre sends the new publications of the Finnish publishing bodies immediately to its exchange partners. When ECSL receives publications from the partners, it forwards them free of charge to the academic libraries that have ordered them from the Centre. Most of the publications are serials, but ECSL exchanges research monographs and monograph series, too.

The tendency in formal literature exchange resembles the situation with ILL in Finland. When the Centre started its activity, it had almost 6,000 international and national exchange points. The number of these points has been diminishing all the time and 2012 was the first year that the number was below 3,000 . In 2018, the number of these points went below 2,000 and the number seems to fall yearly at the rate of $-5 \%$. When the Centre had 13,270 arriving serial publications in 1989, this number has currently decreased to 4057. Because of the historical changes of the Centre and its customer base, these numbers show the direction but are not as exact as the data available relating to the trends in the Finnish ILL.

The organized exchange of publications is an old and traditional form of scholarly communication. Digitalization has affected this practice, but it has not completely disrupted it in Finland. There still seems to be researchers, research areas and libraries that benefit from scientific literature exchange, even though there are fewer and fewer of them. It is interesting to see what will happen to publication exchange if most of the new scholarly papers are going to be available not just digitally, but also in OA.

\section{Finnish researchers and peer-to-peer resource sharing}

The digitalization of the research environment has made it possible to build social media services for researchers and to use general social media (Facebook, LinkedIn, Twitter, etc.) for research-related purposes. Many social media sites facilitate the peer-to-peer sharing of publications and other documents. Academic social networks, such as ResearchGate and Academia. $e d u$, aim their services specifically for researchers. They enable networking and document sharing, within and across

Figure 2 Trends in the digital and printed resource usage in Finland 2002-2018

Resourse usage trends in Finland

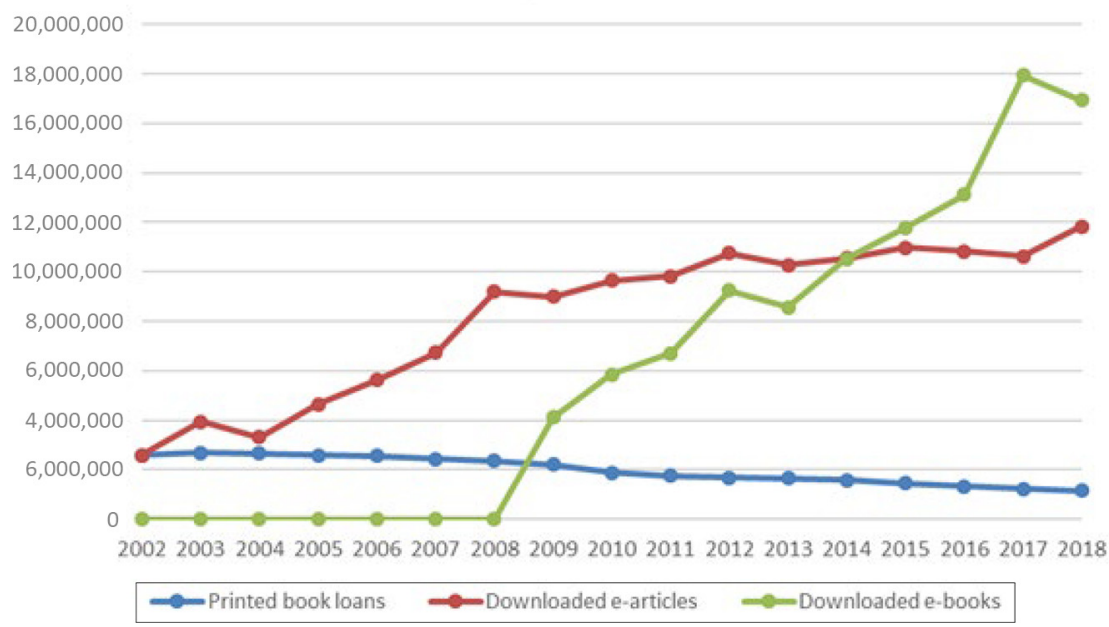


institutional and national boundaries. Some of them are quite loose with copyright, even though they are not breaking the law as openly as Sci-Hub, which is a digital "library" of pirated publications.

On the right side of the law are those pure OA journals and mega journals that often base their business models on Gold $\mathrm{OA}$ and article processing charges (predatory publications might be exceptions in this respect). In addition, preprint servers such as arXiv, as well as the emergence of institutional repositories (and Green OA) also contribute to the fall of library ILL numbers. Google Scholar is the most used tool for researchers (van Noorden, 2014) and its search results often contain publications originating from discipline-based and institutional repositories. Services like Unpaywall and Open Access button are becoming mainstream too.

Perhaps in a $100 \%$ OA world, the traditional ILL for new scholarly publications would no more exist. It is, of course, debatable, when and how this kind of complete flip-over is going to happen or if it is going to take place at all.

The consequence of these developments seems to be that the need for ILL decreases. Unfortunately, the researchers do not have comprehensive statistics of the informal peer-to-peer resource sharing. Scholars have circulated scientific documents via email and file sharing servers as long as the internet has existed, but academic social networks enable resource sharing in a much larger scale and more effectively and easily than has previously been possible. The most popular academic social network is ResearchGate (van Noorden, 2014). It has especially gained users from medicine, physical sciences, life sciences, and engineering (Thelwall and Kousha, 2016), but researchers in many other domains are using it widely, too. As an academic social network, ResearchGate has other functions besides document sharing. These functions include asking and answering questions, browsing for new publications and finding collaborators and job announcements. However, resource sharing and increasing the visibility of one's own work seem to be the leading motives for using ResearchGate.

Table 1 depicts the status of the ResearchGate use in Finland. It includes the number of the ResearchGate users at

Table 1 ResearchGate Use at the Finnish universities

\begin{tabular}{lrcc}
\hline & Users & Publications & $\begin{array}{r}\text { Publication reads } \\
\text { (Week 25) }\end{array}$ \\
\hline Aalto University & 6,257 & 1,553 & 47,520 \\
University of Helsinki & 10,180 & 57398 & 71401 \\
UEF & 4,012 & 5,099 & 22,253 \\
University of Jyväskylä & 3,899 & 3821 & 27,206 \\
University of Lapland & 798 & 239 & 1,989 \\
LUT & 1,942 & 1,604 & 17,356 \\
University of Oulu & 4,182 & 15,855 & 29,145 \\
Hanken & 679 & 89 & 4,149 \\
University of the Arts & 146 & 9 & 281 \\
Tampere University & 5,473 & 16,243 & 33,899 \\
University of Turku & 5,308 & 19,139 & 28,447 \\
University of Vaasa & 958 & 331 & 5,263 \\
Åbo Akademi & 2,005 & 4,686 & 9,823 \\
Total & 45,839 & 126,066 & 298,732 \\
Source: Data collected in June 2019 & & \\
\hline
\end{tabular}

each Finnish university, the number of their publications and the number of the weekly reads of them.

Table 1 shows that the largest and most research-intensive Finnish universities have the most active user population in ResearchGate, i.e. the number of users and publications positively correlates to the general size of the university. Finnish researchers seem to be using ResearchGate widely for increasing the visibility and accessibility of their publications and for finding potential collaborators.

Even though most of the users are whole-time researchers, the users might also hold other positions as librarians, students or administrative personnel in their respective universities. We do not know how many of the publications are available as full texts but preliminary scanning shows that at least researchers with high $R G$ scores (the visibility metric used by ResearchGate) seem to add full texts to ResearchGate regularly. If full text is not included, ResearchGate offers a possibility to request a copy of the publication directly from its author.

The researchers in Finnish universities annually publish about 38000 scholarly articles (Ministry of Education and Culture, 2020). Even though it is hard to estimate the coverage of Finnish publications on ResearchGate based on these numbers, it is safe to say that substantial number of papers is available, and one can easily request more papers from the authors. ResearchGate is currently a much larger distributor of Finnish scientific publications than the ILL system of Finnish University Libraries as a whole, and ResearchGate might even contain some publications that would be difficult to get via traditional ILL means (Figure 3).

Even though some researchers might assume that the papers available in ResearchGate are OA, this is not the case because ResearchGate requires authentication and breaches copyrights in many cases (cf. Piwowar and al. 2018). To use ResearchGate, one must reveal one's identity (or invent a fake one). As we know, the activities, contacts and interests of online identities are the real currency of the Internet Age. In this sense, the social media offers no free lunches to us (Figure 4).

\section{Conclusions}

The analysed data shows the falling of ILL and printed loans as well as the rise of the usage of e-books and e-journals. It seems that traditional ILL has transformed in Finland into a complementary, niche market service. The scholars rely on ILL mostly when they have special needs for printed and rare documents.

Finnish researchers have adopted academic social networks where they can disseminate publications and promote their expertise without institutional intermediaries. The reasons for the popularity of ResearchGate seem to be its' ease of use and the intuitive nature of the user interface. The researchers might be aware of the copyright problems with ResearchGate, but there is need for a deeper analysis of how well they are aware of this situation and their legal obligations. Researchers are especially active in using the networks in peer-to-peer resource sharing, which might be another factor decreasing ILL.

One might wonder how permanently social media type of resource sharing services stores full texts. Can we be sure that all the imported files will be available in the future? We do not know how the business model of ResearchGate will evolve and 
Figure 3 The University of Helsinki institutional page of the member statistics

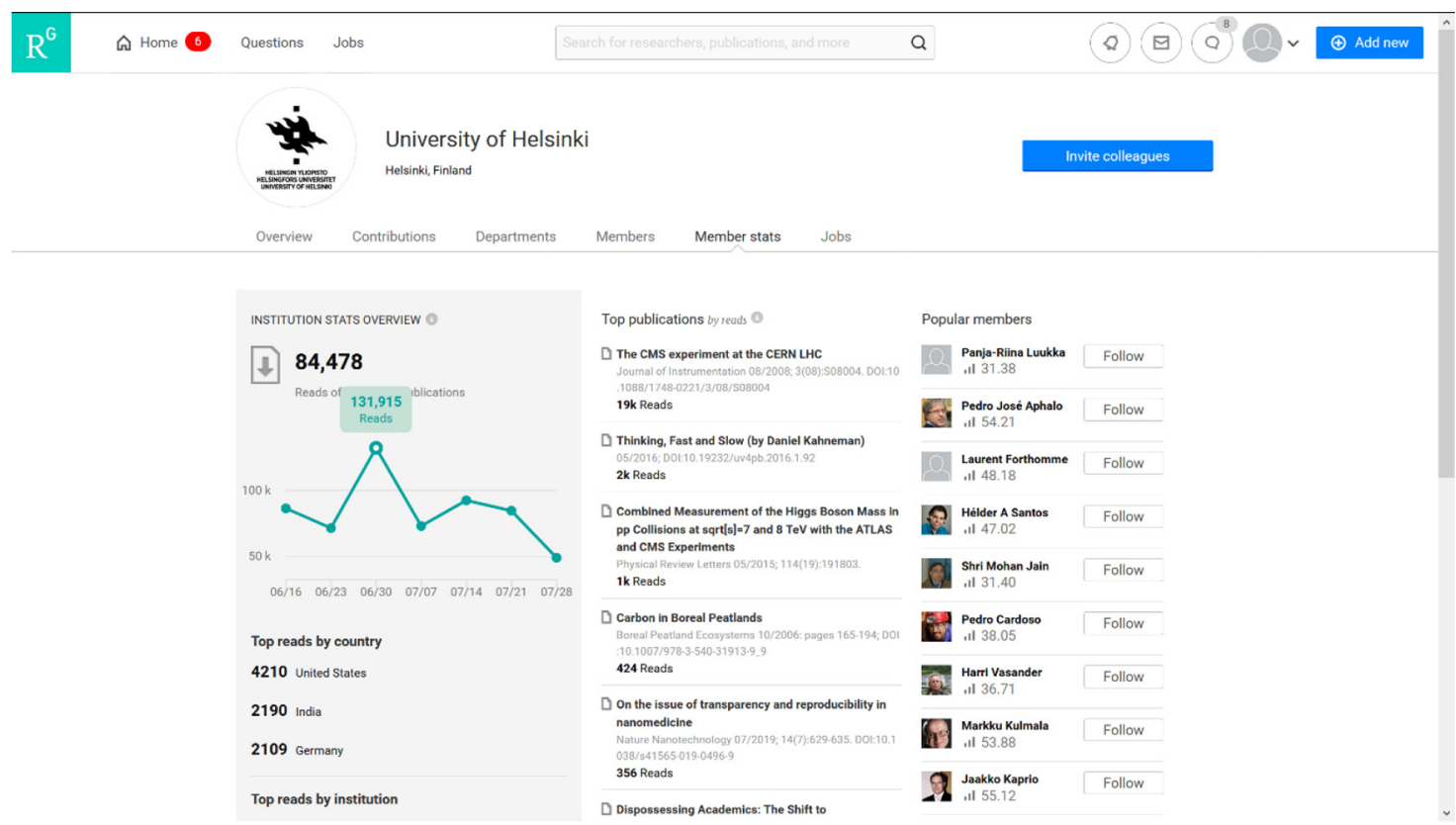

Source: https://www.researchgate.net/institution/University_of_Helsinki in July 26, 2019. ResearchGate collects the number of reads, the top reads by country and by institution weekly. The second top publication of the week 31 is a one-page book review of a popular-scientific book published in UV4 Plants Bulletin

Figure 4 Institutional page of the University of Eastern Finland

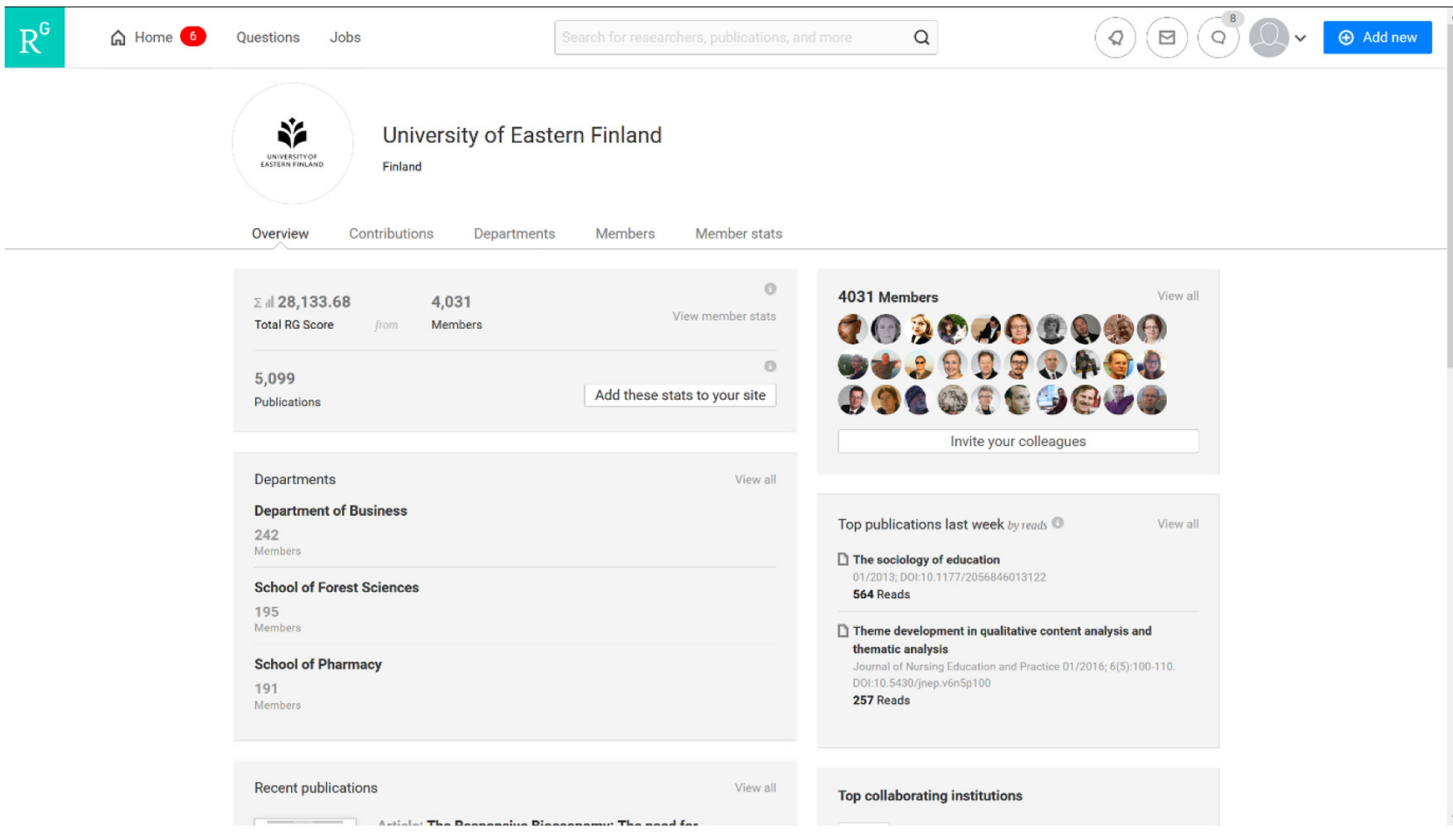

Source: The institutional page of the University of Eastern Finland

(https://www.researchgate.net/institution/University_of_Joensuu) in July 26, 2019

if the whole service even ceases to exist one day. One possible scenario might be that, as has happened with Mendeley, one of the big publishers acquires ResearchGate. Furthermore, it is possible that ResearchGate will not always be as open as it is today. Academia.edu - one the main competitors of ResearchGate - has decided to offer much more services to those users who are willing to upgrade their membership status and to pay for it. 
Legal problems might hinder the use of ResearchGate in the future and endanger the permanent availability of all the documents it contains. Seventeen publishers - including Elsevier, Wiley, BMJ and ACS - formed the Coalition of Responsible Sharing in October 2017 to "address the copyright infringing practices of the ResearchGate site." The coalition is aiming for "a solution that is in the interest of all stakeholders - ResearchGate, publishers and researchers and consistent with access and usage rights." As no one has yet found this solution, the Coalition has forced ResearchGate to remove 1.4 million articles from its site. Nevertheless, the Coalition still sees that ResearchGate contains millions of copyrighted articles "in contravention of agreements between publishers and authors" and that the service is "taking no responsibility for this illicit activity". (Coalition for Responsible Sharing, 2019).

Furthermore, if the $100 \%$ flip over to OA happens, as some have prophesied, or if the amount of OA publications continues to grow as it has been growing (Laakso and Björk, 2016; Piwowar et al., 2018), ILL numbers might fall even faster than thus far.

Because of Plan S and country-based OA mandates, national consortia negotiations have become more difficult than they have been. It is probable that no-deal situations between consortia and big publishers are increasing. The challenge of the consortia is to develop transformative deals with big publishers leading to real immediate $\mathrm{OA}$ and permanent business model change. However, the publishers seem to view $\mathrm{OA}$ as an additional service for which they need more money than what the consortia have paid thus far. Luckily, there are some promising developments, for example, with the Project DEAL in the German context (Taylor, 2019).

The potential difficulties in consortia negotiations might amplify ILL in the future. Anyhow, it is more likely that the researchers will use other legal or illegal means to get the information they need. ILL seems to be too slow for the researchers who are used to the immediate response from the services such as Amazon and Google.

The described developments have consequences to academic libraries, their daily work and services as well as for the resource allocation within the libraries and their host universities. One implication could be that libraries and their host universities invest less money and staff resources to ILL as they have done before. Recently, many Finnish academic libraries have faced funding cuts and devised various kinds of survival strategies. In some cases, the libraries have ceased to exist as separate organizations. There is a need of further research on how the libraries might be changing in the future because of the potentially drastic funding developments and deeper digitalization of all the university activities. The role of ILL in the age of $\mathrm{OA}$ and academic social networks also deserves further research. Unfortunately, it might be difficult to get reliable statistics on the usage these networks.

Another implication of the rise of academic social networks as informal resource sharing tools is that it might generate new kinds of strategic problems for the universities. Besides legal challenges with copyright and user privacy, academic social networks pose other strategic risks. The business models and black-box algorithms of the networks might not align with the basic academic goals and values. The recent landscape analysis of the changes in academic publishing specifically warns that outsourcing certain key functions to private companies may upset the power balance and lead to a situation where the companies are able to influence too much the decisions of the universities. The risk is that the private sector gets too great a role in the analytical assessment of the universities and the performance of their staff and students. (SPARC, 2019.)

Document sharing, reading and the contact networks of researchers are the kinds of data that academic social networks generate and use. When this kind of big brother data gets into the hands of one of the central players in publishing and information analytics businesses, e.g. through company acquisitions and mergers, it might provide an enormous competitive value when combined with other kinds of data and indicators (SPARC, 2019). This may lead into an unhealthy situation in which the publisher knows more about the university than the university itself. As the information professionals realize, it is a short route from knowledge to power.

One implication of the current research is that academic librarians should be more aware of the development and nature of academic social networks. We should be able to give our academics as well as university administration relevant information on the potentials and possible strategic and practical problems of informal resource sharing. Furthermore, we should consider and analyse these new types of environments as a kind of tools for library work in the digital realm.

Even though ILL is not able to compete with academic social networks, it might still be the last resort for our users. Is it not true that we should be able to take care of our users' privacy and to be able to offer our users a legal way to get the information they need?

\section{References}

Baraggioli, J.-L. (2018), "Coordinating a national policy for shared conservation: tools and methods of shared working", in Vattulainen, P. and O'Connor, S. (Eds), Repositories for Print: Strategies for Access, Preservation and Democracy, De Gruyter Saur, München, (Current topics in library and information practice, 9.), pp. 119-128, doi: 10.1515/9783110535372.

Beaubien, A.K., Kuehn, J., Smolow, B. and Ward, S.M. (2006), "Challenges facing high-volume interlibrary loan operations: baseline data and trends in the CIC consortium", College $\mathcal{E}$ Research Libraries, Vol. 67 No. 1, pp. 63-84, doi: 10.5860/crl.67.1.63.

Bjørnshauge, L. (1999), "Opinion paper: from interlending and document delivery to co-operative collections and document access", Interlending \& Document Supply, Vol. 27 No. 1, pp. 30-32, doi: 10.1108/02641619910255847.

Boukacem, C. (2003), "Inter-library loan services and access to electronic resources in French university libraries: a marriage of reason”, Interlending E Document Supply, Vol. 31 No. 4, pp. 218-227, doi: 10.1108/02641610310506942.

Coalition for Responsible Sharing (2019), Status report, 13 June 2019, available at: www.responsiblesharing.org/statusreport-on-researchgate-june-2019/

Connolly, P. (1999), "Interlending and document supply: a review of recent literature - XXXV", Interlending $\mathcal{E}$ 
Document Supply, Vol. 27 No. 1, pp. 33-41, doi: 10.1108/ 02641619910255856.

European Commission (2012), Commission Recommendation of 17.7.2012 on Access to and Preservation of Scientific Information, European Commission, Brussels, available at: http://ec.europa.eu/research/science-society/document_library/ pdf_06/recommendation-access-and-preservation-scientificinformation_en.pdf

European Science Foundation (2020), Plan S: Making Full and Immediate Open Access a Reality, European Science Foundation, Strasbourg, available at: www.coalition-s.org/

Jackson, M. (2004), "The future of interlending", Interlending E Document Supply, Vol. 32 No. 2, pp. 88-93, doi: 10.1108/ 02641610410699272

Laakso, M. and Björk, B.-C. (2016), "Hybrid open access: a longitudinal study", fournal of Informetrics, Vol. 10 No. 4, pp. 919-932, doi: 10.1016/j.joi.2016.08.002.

Ministry of Education and Culture (2020), Vipunen: educational Statistics Finland, Ministry of Education and Culture, Helsinki, available at: https://vipunen.fi/en-gb/ university/Pages/Julkaisut.aspx

Muhonen, A. and Saarti, J. (2016), "The changing paradigm of document delivery: exploring researchers' peer to peer practices", Interlending \& Document Supply, Vol. 44 No. 2, pp. 66-71.

Muhonen, A., Nygrén, U. and Saarti, J. (2011), "Bringing order out of chaos: benchmarking tools used in merging university libraries in Finland", in Woodsworth, A. and David, W. and Bingley, P. (Eds), Librarianship in Times of Crisis: Advances in Librarianship, Vol. 34, Emerald, pp. 183-205.

Parnell, G.S., Bresnick, T.A., et al. (2013), "Introduction to decision analysis", in Parnell, G.S. (Ed.), Handbook of Decision Analysis, Wiley, New York, NY, pp. 4-7.

Piwowar, H., Priem, J., Larivière, V., Alperin, J.P., Matthias, L., Norlander, B., Farley, A., West, J. and Haustein, S. (2018), "The state of OA: a large-scale analysis of the prevalence and impact of open access articles", Peerf, Vol. 6, p. e4375, doi: 10.7717/peerj.4375.

Posner, B. (2014), "The impact of global trends on ILDS", Interlending E Document Supply, Vol. 42 No. 4, pp. 147-152., doi: 10.1108/ILDS-10-2014-0048.

Prowse, S.W. (2000), "Current trends in interlending and document delivery in the UK", Interlending \& Document Supply, Vol. 28 No. 4, pp. 184-192, doi: 10.1108/ 02641610010357130

Saarti, J. (2018), "Collection policies for the post-digital era of academic publishing: future scenarios for the academic libraries", in Vattulainen, P. and O'Connor, S. (Eds), Repositories for Print: Strategies for Access, Preservation and Democracy, De Gruyter Saur, München. (Current topics in library and information practice, 9), pp. 103-112, doi: $10.1515 / 9783110535372-010$

Saarti, J. and Tuominen, K. (2017), "From paper-based towards post-digital scholarly publishing: an analysis of an ideological dilemma and its consequences", Information Research, Vol. 22 No. 3, paper 769, available at: http:// InformationR.net/ir/22-3/paper769.html

Solomon, D.J. (2012), "Digital distribution of academic journals and its impact on scholarly communication: looking back after 20 years", The fournal of Academic Librarianship, Vol. 39 No. 1, pp. 23-28, doi: 10.1016/j.acalib.2012.10.001.

SPARC (2019), "SPARC landscape analysis: the changing academic publication industry - implications for academic institutions", March 28, available at: https://sparcopen.org/ our-work/landscape-analysis/

Taylor, A.P. (2019), "Project DEAL in Germany reaches agreement with springer nature", The Scientist 2019-08-23, available at: www.the-scientist.com/news-opinion/projectdeal-in-germany-reaches-agreement-with-springer-nature66342

Thelwall, M. and Kousha, K. (2016), "ResearchGate articles: age, discipline, audience size and impact", fournal of the Association for Information Science and Technology, Vol. 68 No. 2, pp. 468-479, 2017, doi: 10.1002/asi.23675.

Tuominen, K. and Saarti, J. (2012), " "The Finnish library system: open collaboration for an open society", IFLA fournal, Vol. 38 No. 2, pp. 115-136., doi: 10.1177/ 0340035212444506

Van Noorden, R. (2014), "Online collaboration: scientists and the social network", Nature, Vol. 512 No. 7513, pp. 126-129, doi: 10.1038/512126a.

Vattulainen, P. (2018), "The evolving model of the national repository library of Finland", in Vattulainen, P. and O'Connor, S. (Eds), Repositories for Print: Strategies for Access, Preservation and Democracy, De Gruyter Saur, München, (Current topics in library and information practice, 9), pp. 119-128, doi: 10.1515/9783110535372.

Williams, J.A. and Woolwine, D.E. (2011), "Interlibrary loan in the United States: an analysis of academic libraries in a digital age", Fournal of Interlibrary Loan, Document Delivery E Electronic Reserve, Vol. 21 No. 4, pp. 165-183, doi: 10.1080/ 1072303X.2011.602945.

Yue, P.W. and Syring, M.L. (2004), "Usage of electronic journals and their effect on interlibrary loan", Library Collections, Acquisitions, E Technical Services, Vol. 28 No. 4, pp. 420-432, doi: 10.1080/14649055.2004.10766014.

Zanoni, A.B. (2011), Strategic Analysis: processes and Tools, Routledge, New York, NY.

\section{Corresponding author}

Jarmo Saarti can be contacted at: jarmo.saarti@uef.fi 